УДК 614.8.01:004.946

НАУЧНО-МЕТОДИЧЕСКИЕ ОСНОВЫ МОДЕЛИРОВАНИЯ СЦЕНАРИЕВ ЧРЕЗВЫЧАЙНЫХ СИТУАЦИЙ ДЛЯ ТРЕНАЖЕРОВ СОВМЕСТНОГО ОБУЧЕНИЯ

\title{
SCIENTIFIC AND METHODOLOGICAL FOUNDATIONS OF MODELING OF EMERGENCY SCENARIOS FOR JOINT TRAINING SIMULATORS
}

\section{А.Ю. Котельникова, Д.А. Котельников, С.Ю. Устюжанина}

Уфимский государственный нефтяной технический университет, г. Уфа, Российская Федерация

\section{Anastasia Ju. Kotelnikova, Dmitry A. Kotelnikov, Svetlana Ju. Ustyuzhanina}

Ufa State Petroleum Technological University, Ufa, Russian Federation e-mail: anastasfudo@mail.ru

Аннотация. На современном уровне развития нефтегазовой и нефтеперерабатывающей отрасли предъявляются высокие требования к квалификации оперативно-диспетчерского персонала, умению использовать новые компьютерные продукты и уникальные инновационные технологии. Поэтому разработка новых научнометодических основ для информационных технологий в сфере противопожарной подготовки персонала является актуальным.

Для решения данной задачи ведется создание тренажерного комплекса, позволяющего обучать оперативно-диспетчерский персонал умениям управления, использования информации в команде для минимизации времени реагирования на возникновения ЧС на производстве. 
Такой комплекс является визуально-интерактивной и одновременно обучающей системой, функционирующей на основе смоделированных математических сценариев чрезвычайных ситуаций, что представляет собой ядро процесса обучения и отвечает за адекватность тренажера - его полноту и точность имитации производственного процесса и процесса ликвидации ЧС.

Предложенная впервые основа для разработки тренажера совместной подготовки имеет в своей основе математическую модель реальных физических процессов и поэтому имеет неограниченное развитие в сфере качественного обучения персонала.

Abstract. At the modern level of development of the oil and gas and oil refining industry high demands to qualification of operational dispatching personnel, ability to use new computer products and unique innovative technologies are placed. Therefore, development of new scientific and methodical bases for information technologies in the sphere of fire-prevention training of personnel is relevant.

To solve this problem, a simulator complex is being created that allows operational dispatch personnel to be trained in management skills, using information in a team to minimize response time to emergency situations at work

Such a complex is a visual-interactive and at the same time educational system that functions on the basis of simulated mathematical scenarios of emergency situations, which is the core of the training process and is responsible for the adequacy of the simulator - its completeness and accuracy of imitation of the production process and emergency response process.

The proposed for the first time basis for the development of a joint training simulator is based on a mathematical model of real physical processes and therefore has unlimited development in the field of high-quality personnel training. 
Ключевые слова: компьютерный тренажер, пожарная безопасность, обучение, диспетчер, руководитель тушения пожара, математическое моделирование, сценарии аварий, программный комплекс

Key words: computer simulator, fire safety, training, dispatcher, head of fire extinguishing, mathematical modeling, accident scenarios, software complex

Целью исследования является повышение уровня совместной подготовки оперативного персонала опасных объектов и личного состава пожарной охраны путем моделирования сценариев чрезвычайных ситуаций (ЧС) на нефтегазовых объектах для программного комплекса по совместному обучению.

Научная новизна исследовательской работы заключается в моделировании развития чрезвычайных ситуаций с помощью дискретнодинамических моделей на основе сетей Петри, а также в разработке принципов ситуационного моделирования при создании имитационных моделей для тренажера по совместному обучению оперативного персонала на основе графоаналитического метода.

В настоящее время одним из наиболее эффективных методов совместного обучения личного состава пожарных подразделений и оперативного-диспетчерского персонала предприятий нефтегазовых предприятий является проведение обучения с использованием современных компьютерных технологий, основывающихся на моделировании сценариев чрезвычайных ситуаций на реальных функционирующих опасных объектах $[1,2]$.

Для создания моделей чрезвычайных ситуаций для Веб-приложения были смоделированы два сценария на объекте нефтехимии ЛПДС «Черкассы-ПП» УПО АО «Транснефть-Урал», расположенного в промзоне п. Новые Черкассы Республики Башкортостан. ЛПДС «Черкассы» представляет собой комплекс сооружений и устройств для 
приема, хранения, налива и транспортировки легких нефтепродуктов по магистральным нефтепродуктопроводам.

Сценарии чрезвычайных ситуаций для построения основного задания тренажерного комплекса позволят проверить навыки оперативнодиспетчерского персонала и специалистов в области тушения и высшего управления.

Для обучения персонала проведено вероятностное моделирование с помощью построения и расчёта «деревьев отказа» и «деревьев событий» на основе анализа статистических данных по нефтегазовой отрасли и основных причин аварийности резервуаров и насосов в насосных помещениях.

Основная задача компьютерного тренажерного комплекса заключается в обучении и закреплении знаний оперативно-диспетчерского персонала по эффективному и безопасному ведению технологического процесса нефтегазовых объектов.

Актуальной проблемой является принятие рационального решения научно-практической задачи по созданию обучающих, имитационноинформационных компьютерных тренажеров, работающих в условиях реального времени.

Причина популярности компьютерных тренажеров для обучения персонала довольно очевидна:

- при использовании тренажеров обучаемый приобретает важные навыки и умения по управлению объектом не только в штатных, но и в аварийных ситуациях с гарантированным уровнем его безопасности, что является невозможным при обучении персонала на реальных объектах отрасли;

- применение тренажеров значительно повышает качество обучения при незначительном повышении его цены;

- тренажер является единственным средством обучения, который позволяет отрабатывать весь спектр профессиональных навыков 
оперативных работников предприятий - от понятийных до моторных, то есть вырабатывать и закреплять навыки принятия решений и управления объектом. Ключевыми моментами в применении обучающего тренажера являются использование сценариев по моделированию аварийных ситуаций и изучение методов их устранения [3, 4].

Создание единой постоянно обновляемой базы данных для диспетчеров пожарных частей о состоянии гарнизона, оперативный просчет времени и путей до опасного объекта помогут своевременно принимать решения и проводить оценку обстановки [5].

Для решения данных задач ведется создание тренажерного комплекса, который позволит оперативно передавать информацию от диспетчера потенциально опасного объекта к диспетчеру пожарной части, а далее информировать руководителя тушения пожара для отработки дальнейших действий по локализации и ликвидации чрезвычайных ситуаций [6]. Для осуществления функционирования тренажерного комплекса с помощью спрогнозированных сценариев и вероятностных моделей создаются математические модели.

Создание математической модели ЧС включает в себя несколько этапов:

- этап 1. Содержательное описание ЧС на основе всех имеющихся о ней знаний, результатов обследований сходных ситуаций, консультаций с экспертами, изучения справочной и специальной литературы;

- этап 2. Формализация содержательного описания модели и математическая постановка задачи;

- этап 3. Преобразование схемы ЧС в математическую модель с помощью выражений, неравенств, уравнений, алгоритмов, схем;

- этап 4. Исследование модели путем многовариантных расчетов для изучения свойств модели и ее поведения при различных условиях; 
- этап 5. Проведение идентификации ЧС путем сопоставления результатов экспериментов и имеющихся опытных данных, уточнение параметров модели, отладка и проверка адекватности.

После того как проверена адекватность модели, начинается использование модели для анализа и прогнозирования ЧС, происходящих в реальных условиях $[7,8]$.

Для математического моделирования развития чрезвычайной ситуации в тренажерном комплексе целесообразно использовать дискретные динамические модели, построенные на основе метода сетей Петри.

Сети Петри является математическим аппаратом для осуществления моделирования динамических дискретных систем [9].

Моделирование в сетях Петри осуществляется на событийном уровне. Определяются, какие действия происходят в системе, какие состояния предшествовали этим действиям и какие состояния примет система после выполнения действия. Анализируя результаты выполнения, можно сказать о том, в каких состояниях пребывала или не пребывала система, какие состояния в принципе не достижимы [10]. В основе исследования перечисленных свойств лежит анализ достижимости. Методы анализа свойств сетей Петри основаны на использовании графов достижимых (покрывающих) маркировок, решении уравнения состояний сети и вычислении линейных инвариантов позиций и переходов. Каждому условию в сети Петри соответствует определенная позиция. Совершению события соответствует срабатывание перехода, при котором маркеры из входных позиций этого перехода перемещаются в выходные позиции. Последовательность событий образует моделируемый процесс [11].

Таким образом, сети Петри - это аппарат для моделирования динамических дискретных систем.

Динамическая система предназначена для описания и изучения систем, изменяющихся с течением времени. Динамическая система описывает динамику некоторого процесса или состояния, т.е. процесс перехода 
системы из одного состояния в другое. Дискретная система (каскад) поведение системы описывается последовательностью состояния [12].

Дискретно-динамическая система на основе сети Петри включает в себя:

- позиция - промежуточное состояние развития опасных факторов ЧС;

- переходы - процесс взаимодействия состояний, процессы развития ЧС;

- параметры меток - изменяющиеся во времени характеристики ЧС; входные параметры модели - начальные характеристики ЧС;

- выходные параметры - потери в результате действия опасных факторов ЧС [13].

В сетях Петри события и условия представляются абстрактными символами двух непересекающихся множеств - множества переходов и множества позиций, которые обозначаются $\mathrm{T}=\left\{\mathrm{t}_{0}, \mathrm{t}_{1}, \ldots, \mathrm{t}_{\mathrm{n}}\right\}$ и $\mathrm{P}=\left\{\mathrm{p}_{0}, \mathrm{p}_{1}, \ldots, \mathrm{p}_{\mathrm{n}}\right\}$ соответственно $[14,15]$.

Фундаментальное уравнение сети Петри (уравнение Мураты) [16, 17] может быть представлено в следующем виде (1):

$$
\mathrm{x} \cdot \mathrm{A}=\Delta \mu
$$

где $\Delta \mu=\mu-\mu_{0}$;

x - вектор счёта срабатываний переходов;

А - транспонированная матрица инцидентности, либо матрица инцидентности двойственной сети Петри.

Каждое уравнение системы соответствует переходу двойственной сети Петри.

Для математического моделирования чрезвычайных ситуаций при разгерметизации резервуара и разгерметизации насоса построены сети Петри (рисунки 1, 2), которые используются в программном комплексе при решении первого и второго сценариев. Параметры состояний и переходов приведены в таблицах 1 и 2. 
Таблица 1. Параметры сети Петри при разгерметизации резервуара

\begin{tabular}{|c|c|c|c|}
\hline \multicolumn{2}{|r|}{ Состояние } & \multicolumn{2}{|r|}{ Переход } \\
\hline $\mathrm{P} 0$ & Безаварийное состояние & T0 & Хрупкое разрушение \\
\hline P1 & $\begin{array}{c}\text { Возникновение коррозии, заводских } \\
\text { дефектов, образование трещин }\end{array}$ & $\mathrm{T} 1$ & Природное явление \\
\hline $\mathrm{P} 2$ & $\begin{array}{c}\text { Возникновение природных } \\
\text { катаклизмов }\end{array}$ & $\mathrm{T} 2$ & Дефект монтажа \\
\hline $\mathrm{P} 3$ & Несоблюдение правил монтажа & $\mathrm{T} 3$ & Нарушение правил эксплуатации \\
\hline P4 & $\begin{array}{c}\text { Нарушение правил } \\
\text { противопожарной безопасности }\end{array}$ & $\mathrm{T} 4$ & Разгерметизация резервуара \\
\hline P5 & $\begin{array}{c}\text { Аварийное состояние при хрупком } \\
\text { разрушении }\end{array}$ & T5 & $\begin{array}{l}\text { Полное разрушение резервуара с } \\
\text { истечением дизельного топлива }\end{array}$ \\
\hline P6 & $\begin{array}{c}\text { Аварийное состояние при } \\
\text { природных явлениях }\end{array}$ & T6 & Мгновенное воспламенение \\
\hline P7 & $\begin{array}{c}\text { Аварийное состояние при дефекте } \\
\text { монтажа }\end{array}$ & $\mathrm{T} 7$ & Не мгновенное воспламенение \\
\hline P8 & $\begin{array}{c}\text { Аварийное состояние при } \\
\text { нарушении правил эксплуатации }\end{array}$ & $\mathrm{T} 8$ & Пролив дизельного топлива \\
\hline P9 & $\begin{array}{c}\text { Состояние полной разгерметизации } \\
\text { резервуара }\end{array}$ & T9 & Пролив дизельного топлива \\
\hline $\mathrm{P} 10$ & Вытекание дизельного топлива & $\mathrm{T} 10$ & Вскипание дизельного топлива \\
\hline P11 & $\begin{array}{c}\text { Возникновение условий возгорания } \\
\text { дизельного топлива }\end{array}$ & T11 & $\begin{array}{c}\text { Не вскипание дизельного } \\
\text { топлива }\end{array}$ \\
\hline P12 & $\begin{array}{l}\text { Возникновение условий вспышки } \\
\text { дизельного топлива с задержкой }\end{array}$ & T12 & Взрыв паров \\
\hline P13 & $\begin{array}{c}\text { Условия для возникновения пожара } \\
\text { пролива } \\
\end{array}$ & T13 & Конец горения \\
\hline P14 & $\begin{array}{c}\text { Повышение концентрации } \\
\text { взрывоопасных паров } \\
\text { над поверхностью нефтепродукта }\end{array}$ & T14 & Конец горения \\
\hline P15 & Условия прекращения горения & T15 & Конец рассеивание паров \\
\hline P16 & $\begin{array}{c}\text { Условия для возникновения пожара } \\
\text { пролива }\end{array}$ & \multirow{3}{*}{ T16 } & \multirow{3}{*}{ Ликвидация ЧС } \\
\hline P17 & Рассеивание паров & & \\
\hline P18 & $\begin{array}{c}\text { Создание условий для ликвидации } \\
\text { ЧС }\end{array}$ & & \\
\hline
\end{tabular}




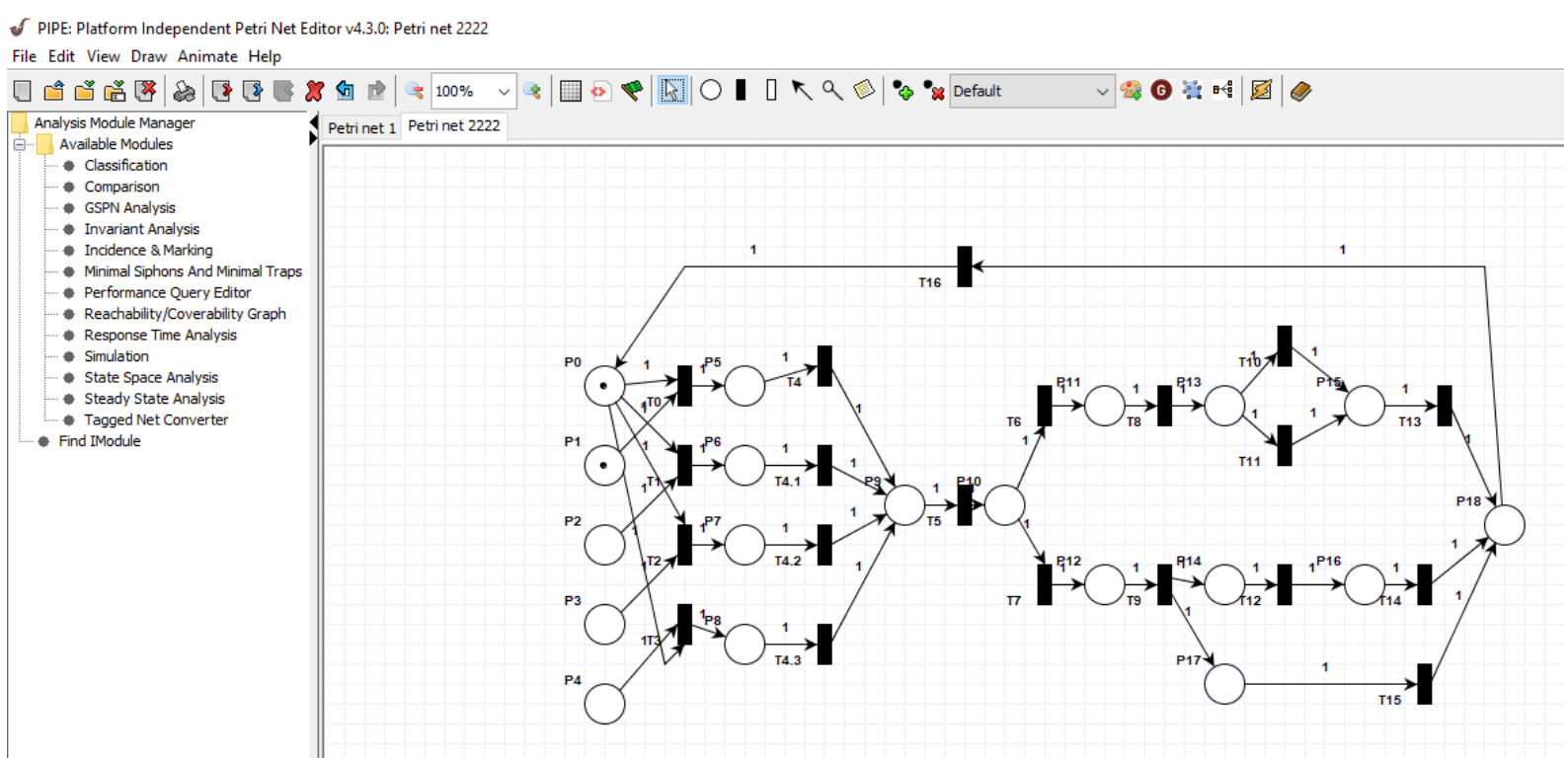

$\mathrm{P}$ - состояние; Т - процесс преобразования (физико-химические процессы развития ЧС и другие процессы) состояния

\section{Рисунок 1. Сеть Петри при разгерметизации резервуара с дизельным топливом}

Таблица 2. Параметры сети Петри при разгерметизации насоса

\begin{tabular}{|c|c|c|c|}
\hline \multicolumn{2}{|c|}{ Состояние } & \multicolumn{2}{c|}{ Переход } \\
\hline P0 & Безаварийное состояние & Т0 & Приозия \\
\hline P1 & $\begin{array}{c}\text { Возникновение механических } \\
\text { повреждений }\end{array}$ & Т1 & явление \\
\hline P2 & $\begin{array}{c}\text { Возникновение внешних } \\
\text { воздействий }\end{array}$ & Т2 & Износ запорного устройства \\
\hline P3 & $\begin{array}{c}\text { Возникновение износа запорных } \\
\text { устройств }\end{array}$ & Т3 & Ошибка при сборке насоса \\
\hline P4 & Брак в монтажных работах & Т4 & Ошибка персонала \\
\hline P5 & $\begin{array}{c}\text { Нарушение технической } \\
\text { эксплуатации }\end{array}$ & Т5 & Полная разгерметизация насоса \\
\hline P6 & $\begin{array}{c}\text { Аварийное состояние при } \\
\text { механических повреждениях }\end{array}$ & Т6 & Полная разгерметизация насоса \\
\hline P7 & $\begin{array}{c}\text { Аварийное состояние внешних } \\
\text { воздействиях }\end{array}$ & Т7 & Мгновенное воспламенение \\
\hline P8 & $\begin{array}{c}\text { Аварийное состояние при износе } \\
\text { запорных устройств }\end{array}$ & Т8 & Не мгновенное воспламенение \\
\hline P9 & $\begin{array}{c}\text { Аварийное состояние при браке в } \\
\text { монтажных работах }\end{array}$ & Т9 & Факельное горение \\
\hline
\end{tabular}


Продолжение таблицы 2

\begin{tabular}{|c|c|c|c|}
\hline P10 & $\begin{array}{c}\text { Аварийное состояние } \\
\text { при нарушении технической } \\
\text { эксплуатации }\end{array}$ & $\mathrm{T} 10$ & Пожар пролива \\
\hline P11 & $\begin{array}{c}\text { Состояние полной } \\
\text { разгерметизации насоса }\end{array}$ & $\mathrm{T} 11$ & Прекращение горения \\
\hline P12 & Вытекание дизельного топлива & $\mathrm{T} 12$ & Тепловое воздействие \\
\hline P13 & $\begin{array}{c}\text { Возникновение условий } \\
\text { возгорания дизельного топлива }\end{array}$ & $\mathrm{T} 13$ & Прекращение горения \\
\hline P14 & $\begin{array}{c}\text { Возникновение условий } \\
\text { возгорания дизельного топлива } \\
\text { с задержкой }\end{array}$ & $\mathrm{T} 14$ & Тепловое воздействие \\
\hline P15 & $\begin{array}{c}\text { Условия сгорания дизельного } \\
\text { топлива }\end{array}$ & $\mathrm{T} 15$ & Образование пролива \\
\hline P16 & $\begin{array}{c}\text { Условия сгорания дизельного } \\
\text { топлива }\end{array}$ & $\mathrm{T} 16$ & $\begin{array}{c}\text { Образование первичного } \\
\text { парогазового облака }\end{array}$ \\
\hline P17 & $\begin{array}{c}\text { Условия для образования пожара } \\
\text { пролива }\end{array}$ & $\mathrm{T} 17$ & Прекращение горения \\
\hline P18 & $\begin{array}{c}\text { Условия для образования } \\
\text { парогазового облака }\end{array}$ & $\mathrm{T} 18$ & Тепловое воздействие \\
\hline P19 & $\begin{array}{c}\text { Условия для возникновения } \\
\text { взрыва }\end{array}$ & $\mathrm{T} 19$ & Взрыв парогазового облака \\
\hline \multirow{4}{*}{ P20 } & \multirow{4}{*}{$\begin{array}{c}\text { Создание условий } \\
\text { для ликвидации ЧС }\end{array}$} & $\mathrm{T} 20$ & Рассеивание парогазового облака \\
\hline & & $\mathrm{T} 21$ & Взрыв парогазового облака \\
\hline & & $\mathrm{T} 22$ & $\begin{array}{c}\text { Рассеивание парогазового облака без } \\
\text { последствий }\end{array}$ \\
\hline & & $\mathrm{T} 23$ & Ликвидация ЧС \\
\hline
\end{tabular}

После визуального построения математической модели сети Петри двух сценариев ЧС рассчитывается фундаментальное уравнение сети для нахождения векторов срабатывания переходов.

В качества примера вычисления фундаментального уравнения для разработанной сети Петри (рисунок 2) рассчитаем только одну ветвь данной системы. 
$\checkmark$ PIPE: Platform Independent Petri Net Editor v4.3.0: Petri net 1

File Edit View Draw Animate Help

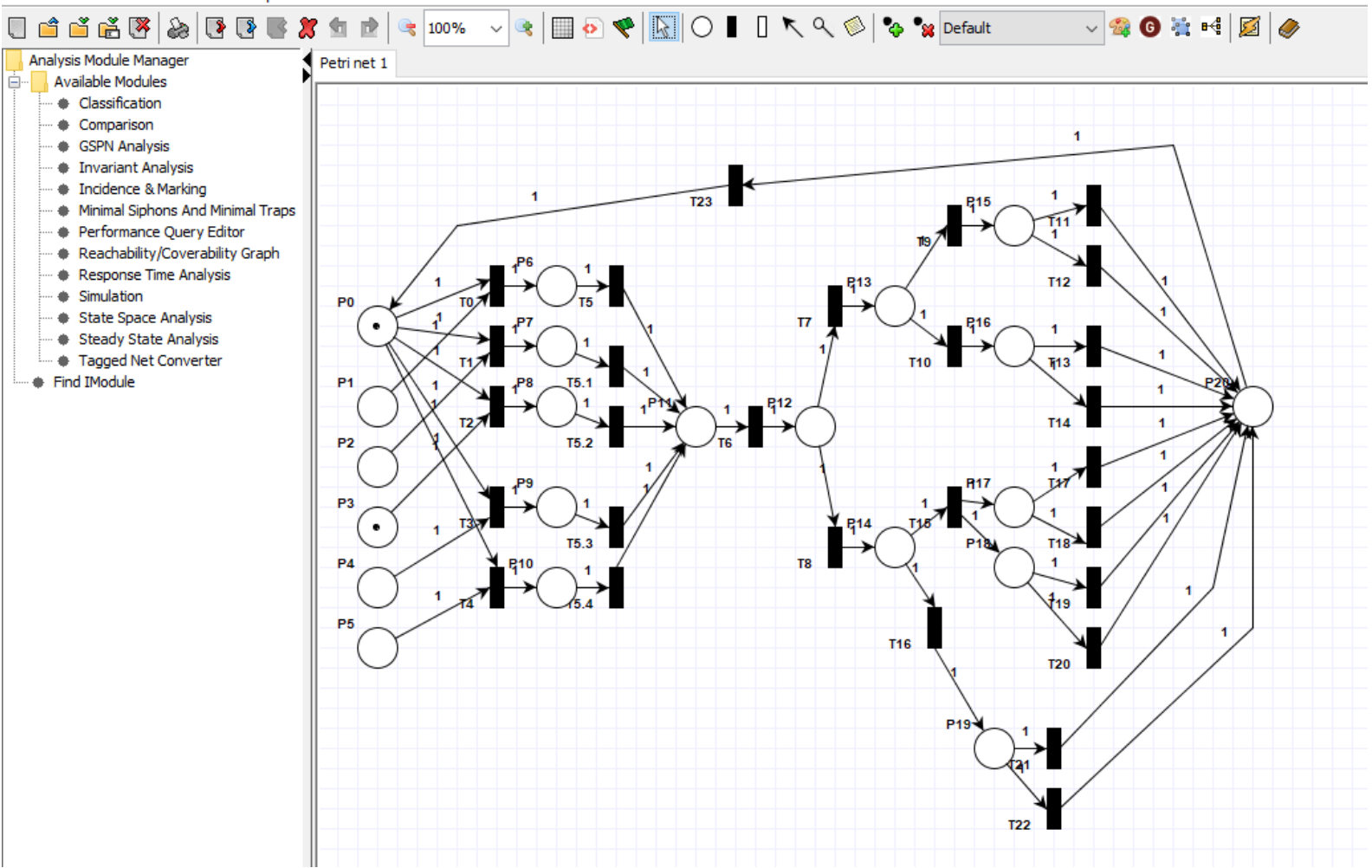

Рисунок 2. Сеть Петри при разгерметизации насоса с дизельным топливом

Подобным образом рассчитываются остальные ветви сети Петри.

Назовем ветвь, где состояние начинается с Р0 как С. Данной ветви соответствуют состояния $P=\{P 0, P 5, P 9, P 10, P 11, P 13, P 15, P 18\}$ и переходы $T=\{T 0, T 4, T 59, T 6, T 8, T 10, T 13, T 16\}$. Начальная маркировка сети обозначается вектором $\mu_{0}\left[\mu_{0}, \mu_{5}, \mu_{9}, \mu_{10}, \mu_{11}, \mu_{13}, \mu_{15}, \mu_{18}\right]$, $\mu_{0}[1,0,0,0,0,0,0,0][17]$.

При аналитическом способе задания ветвь сети Петри задается как $C=\left(P, T, F, H, \mu_{0}\right)$, где, кроме множеств позиций $P$ и переходов $T$, задаются входная $F$ и выходная $H$ функции. Через $F\left(t_{j}\right)$ обозначается множество входных позиций, а через $H\left(t_{j}\right)$ - множество выходных позиций перехода $t_{j} ; \mu_{0}$ - начальная маркировка сети: $F\left(t_{0}\right)=\left\{p_{0}\right\}, H\left(t_{0}\right)=\left\{p_{5}\right\}$; $F\left(t_{4}\right)=\{p 5\}, H\left(t_{4}\right)=\left\{p_{9}\right\} ; F\left(t_{5}\right)=\{p 9\}, H\left(t_{5}\right)=\left\{p_{10}\right\} ; F\left(t_{6}\right)=\left\{p_{10}\right\}$, $H\left(t_{6}\right)=\left\{p_{11}\right\} ; F\left(t_{8}\right)=\left\{p_{11}\right\}, H\left(t_{8}\right)=\left\{p_{13}\right\} ; F\left(t_{10}\right)=\left\{p_{13}\right\}, H\left(t_{10}\right)=\left\{p_{15}\right\} ;$ $F\left(t_{13}\right)=\left\{p_{15}\right\}, H\left(t_{13}\right)=\left\{p_{18}\right\} ; F\left(t_{16}\right)=\left\{p_{18}\right\}, H\left(t_{16}\right)=\left\{p_{0}\right\}$. 
Матричная форма определения сети Петри эквивалентна аналитическому способу задания $C=\left(P, T, A^{-}, A^{+}, \mu_{0}\right)$.

Здесь $A^{-}$и $A^{+}$- матрицы входных и выходных инциденций соответственно размером $m \times n$, где $m$ - число переходов и $n-$ число позиций.

Элемент $d_{i j}{ }^{-}$матрицы $A^{-}$равен кратности дуг, входящих в $i$-й переход из $j$-й позиции.

Элемент $d_{i j}^{+}$матрицы $A^{+}$равен кратности дуг, выходящих из $i$-го перехода в $j$-ю позицию.

Тогда для рассматриваемой сети Петри получены следующие матрицы $A^{-}$и $A^{+}$:

$\begin{array}{rcccccccc} & P_{0} & P_{5} & P_{9} & P_{10} & P_{11} & P_{13} & P_{15} & P_{18} \\ T_{0} & 0 & 1 & 0 & 0 & 0 & 0 & 0 & 0 \\ T_{4} & 0 & 0 & 1 & 0 & 0 & 0 & 0 & 0 \\ T_{5} & 0 & 0 & 0 & 1 & 0 & 0 & 0 & 0 \\ A^{+}=T_{6} & 0 & 0 & 0 & 0 & 1 & 0 & 0 & 0 \\ T_{8} & 0 & 0 & 0 & 0 & 0 & 1 & 0 & 0 \\ T_{10} & 0 & 0 & 0 & 0 & 0 & 0 & 1 & 0 \\ T_{13} & 0 & 0 & 0 & 0 & 0 & 0 & 0 & 1 \\ T_{16} & 1 & 0 & 0 & 0 & 0 & 0 & 0 & 0\end{array}$,

$$
\begin{array}{rcccccccc} 
& P_{0} & P_{5} & P_{9} & P_{10} & P_{11} & P_{13} & P_{15} & P_{18} \\
T_{0} & 1 & 0 & 0 & 0 & 0 & 0 & 0 & 0 \\
T_{4} & 0 & 1 & 0 & 0 & 0 & 0 & 0 & 0 \\
T_{5} & 0 & 0 & 1 & 0 & 0 & 0 & 0 & 0 \\
A^{-}=T_{6} & 0 & 0 & 0 & 1 & 0 & 0 & 0 & 0 \\
T_{8} & 0 & 0 & 0 & 0 & 1 & 0 & 0 & 0 \\
T_{10} & 0 & 0 & 0 & 0 & 0 & 1 & 0 & 0 \\
T_{13} & 0 & 0 & 0 & 0 & 0 & 0 & 1 & 0 \\
T_{16} & 0 & 0 & 0 & 0 & 0 & 0 & 0 & 1
\end{array} .
$$


Матрица $A=A^{+}-A^{-}$(3) называется матрицей инцидентности сети Петри:

$\begin{array}{rcccccccc} & P_{0} & P_{5} & P_{9} & P_{10} & P_{11} & P_{13} & P_{15} & P_{18} \\ T_{0} & -1 & 1 & 0 & 0 & 0 & 0 & 0 & 0 \\ T_{4} & 0 & -1 & 1 & 0 & 0 & 0 & 0 & 0 \\ T_{5} & 0 & 0 & -1 & 1 & 0 & 0 & 0 & 0 \\ A=T_{6} & 0 & 0 & 0 & -1 & 1 & 0 & 0 & 0 \\ T_{8} & 0 & 0 & 0 & 0 & -1 & 1 & 0 & 0 \\ T_{10} & 0 & 0 & 0 & 0 & 0 & -1 & 1 & 0 \\ T_{13} & 0 & 0 & 0 & 0 & 0 & 0 & -1 & 1 \\ T_{16} & 0 & 0 & 0 & 0 & 0 & 0 & 0 & -1\end{array}$

При умножении первой строки матрицы $A^{-}$на определитель получим значение конечной маркировки для первого состояния и, следовательно, для других восьми состояний:

$$
\begin{aligned}
& {[10000000] \cdot A=\mu_{1}, \mu_{1}=[-11000000] ;} \\
& {[01000000] \cdot A=\mu_{2}, \mu_{2}=[0-1100000] ;} \\
& {[00100000] \cdot A=\mu_{3}, \mu_{3}=[00-110000] ;} \\
& {[00010000] \cdot A=\mu_{4}, \mu_{4}=[000-11000] ;} \\
& {[00001000] \cdot A=\mu_{5}, \mu_{5}=[0000-1100] ;} \\
& {[00000100] \cdot A=\mu_{6}, \mu_{6}=[00000-110] ;} \\
& {[00000010] \cdot A=\mu_{7}, \mu_{7}=[000000-11] ;} \\
& {[00000001] \cdot A=\mu_{8}, \mu_{8}=[0000000-1] .}
\end{aligned}
$$

По преобразованной формуле (12) находим восемь векторов срабатывания переходов $\left(\mathrm{x}_{1}-\mathrm{x}_{8}\right)$ :

$$
\mathrm{x}_{1}=\left(\mu_{1}-\mu_{0}\right) / A,
$$




$$
\begin{aligned}
& \begin{array}{llllllll}
P_{0} & P_{5} & P_{9} & P_{10} & P_{11} & P_{13} & P_{15} & P_{18}
\end{array} \\
& \begin{array}{lllllllll}
T_{0} & -1 & 1 & 0 & 0 & 0 & 0 & 0 & 0
\end{array} \\
& \begin{array}{lllllllll}
T_{4} & 0 & -1 & 1 & 0 & 0 & 0 & 0 & 0
\end{array}
\end{aligned}
$$

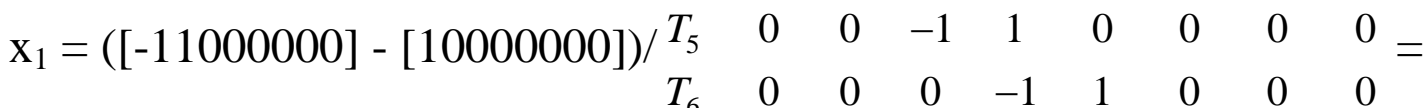

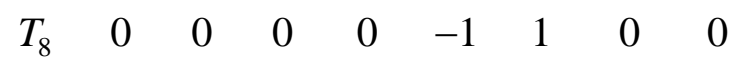

$$
\begin{aligned}
& \begin{array}{lllllllll}
T_{10} & 0 & 0 & 0 & 0 & 0 & -1 & 1 & 0
\end{array} \\
& \begin{array}{lllllllll}
T_{13} & 0 & 0 & 0 & 0 & 0 & 0 & -1 & 1
\end{array}
\end{aligned}
$$

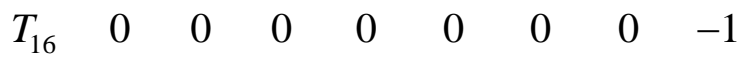

$$
\begin{aligned}
& =[11 / 61 / 3-1 / 12-1 / 12-1 / 12-1 / 12-1 / 12-1 / 12], \\
& \mathrm{x}_{2}=\left(\mu_{2}-\mu_{0}\right) / A \text {, }
\end{aligned}
$$

Вычисленные аналогично $\mathrm{x}_{1}$ значения всех восьми векторов срабатывания переходов сведены в таблицу 3.

Таблица 3. Результаты вычисленных значений векторов срабатывания переходов

\begin{tabular}{|c|c|}
\hline Вектор перехода, $\mathrm{x}_{\mathrm{n}}$ & Значение \\
\hline $\mathrm{x}_{1}$ & {$[11 / 61 / 3-1 / 12-1 / 12-1 / 12-1 / 12-1 / 12-1 / 12]$} \\
\hline $\mathrm{x}_{2}$ & {$[5 / 65 / 6-7 / 12-1 / 12-1 / 12-1 / 12-1 / 12-1 / 12]$} \\
\hline $\mathrm{x}_{3}$ & {$[5 / 61 / 35 / 12-7 / 12-1 / 12-1 / 12-1 / 12-1 / 12]$} \\
\hline $\mathrm{x}_{4}$ & {$[5 / 61 / 3-1 / 125 / 12-7 / 12-1 / 12-1 / 12-1 / 12]$} \\
\hline $\mathrm{x}_{5}$ & {$[5 / 61 / 3-1 / 12-1 / 125 / 12-7 / 12-1 / 12-1 / 12]$} \\
\hline $\mathrm{x}_{6}$ & {$[5 / 61 / 3-1 / 12-1 / 12-1 / 125 / 12-7 / 12-1 / 12]$} \\
\hline $\mathrm{x}_{7}$ & {$[5 / 61 / 3-1 / 12-1 / 12-1 / 12-1 / 125 / 12-7 / 12]$} \\
\hline $\mathrm{x}_{8}$ & {$[2 / 31 / 6-1 / 6-1 / 6-1 / 6-1 / 6-1 / 61 / 3]$} \\
\hline
\end{tabular}

Матричный метод является наиболее перспективными для анализа моделей Петри большой размерности. Фундаментальное уравнение сетей Петри представляет собой систему линейных диофантовых уравнений [18]. Именно поэтому решение сетей Петри вручную является трудоемким и продолжительным процессом, чем применение различных программных комплексов, таких как Petri .NET Simulator 2.0, PIPE, VisualPetri, CPNTools.

В этапы создания тренажерного комплекса входит решение следующих задач: 
- разработка архитектуры и структуры работы веб-сайта с тестами и заданиями;

- разработка, заданий для обучаемых веб-сайта;

- разработка веб-сайта с обучающей игрой.

Использование компьютерного тренажера в виде веб-приложения обеспечивает:

- облегчение освоения общей теории и концепции технологического процесса;

- улучшение понимания системы управления;

- повышение опыта, уверенности и точности действий оперативного персонала в нормальных и нештатных условиях течения процесса;

- улучшение диагностического навыка [19].

Упрощенная структура тренажерного комплекса состоит из следующих основных элементов:

- сервер моделирования ситуаций на опасном объекте, предназначенный для имитационного моделирования аварий на технологических процессах;

- станция оператора-диспетчера, предназначенная для реализации функций человеко-машинного интерфейса;

- станция диспетчера пожарной части, предназначенная для имитации осуществления действий по вызову и распределению пожарных сил;

- станция руководителя тушения пожара, предназначенная для имитации осуществления действий по обработке информации от диспетчера ПЧ и действий по управлению силами и средствами для локализации и ликвидации аварии;

- станция инструктора предназначена для организации и управления процессом обучения операторов-диспетчеров [19].

Архитектура разрабатываемого тренажерного комплекса, представленная на рисунке 3 , включает в себя источники информации в виде различных моделей, входящие в состав ПО и позволяющие 
моделировать определенное явление или устройство, a также все управляющие действия операторов, руководителей и обучаемых, влияющие на изменение хода тренировки и свойств объектов моделирования.

В процессе работы системы модели должны взаимодействовать, получая входные данные, возвращать результаты своей работы для дальнейшего функционирования других моделей. Выходные данные моделей должны доставляться на один или несколько компьютеров одновременно, входные данные для моделей могут доставляться из различных подсистем тренажера (рисунки 4, 5) [20-22].

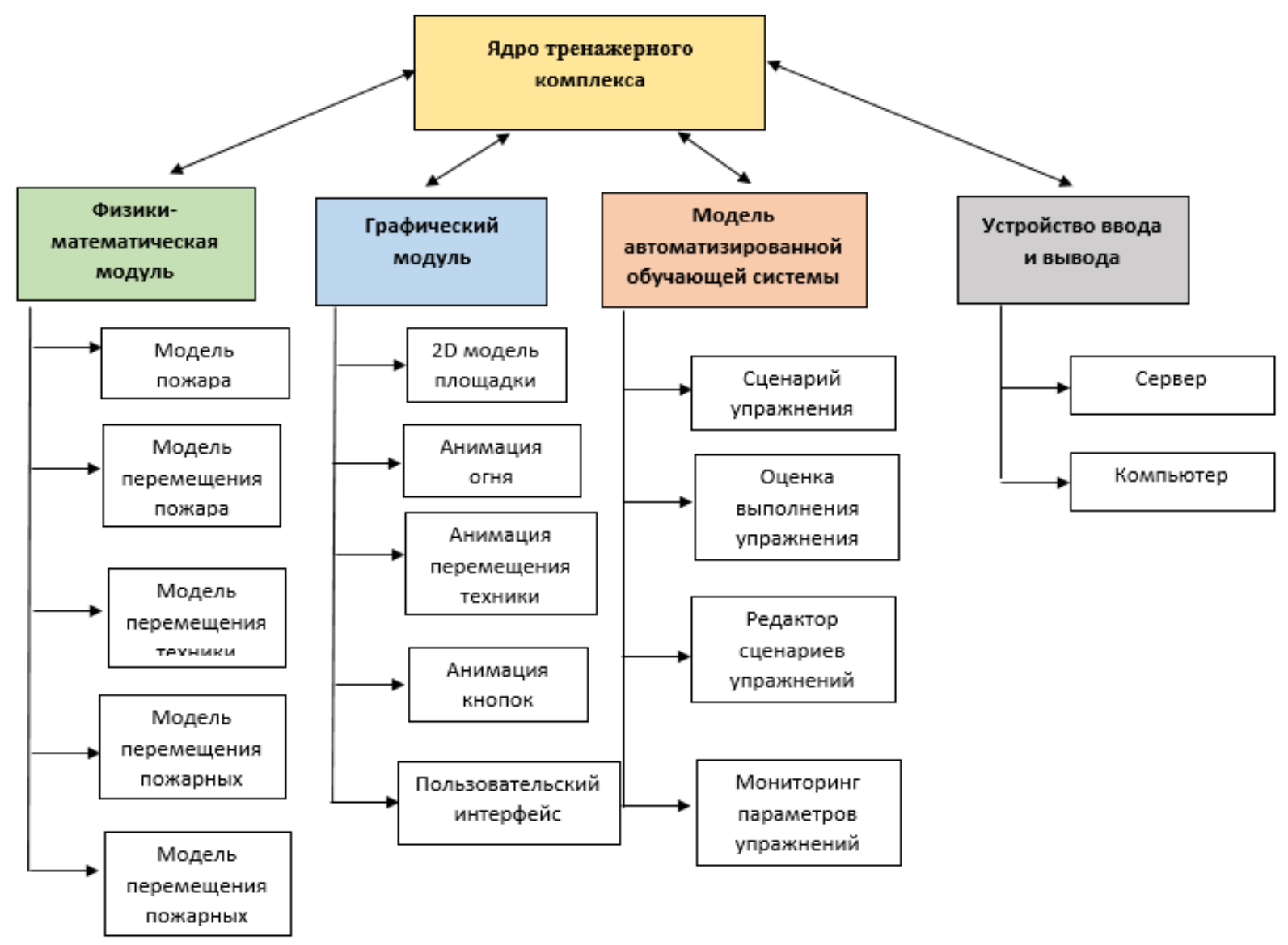

Рисунок 3. Архитектура компьютерного тренажерного комплекса 


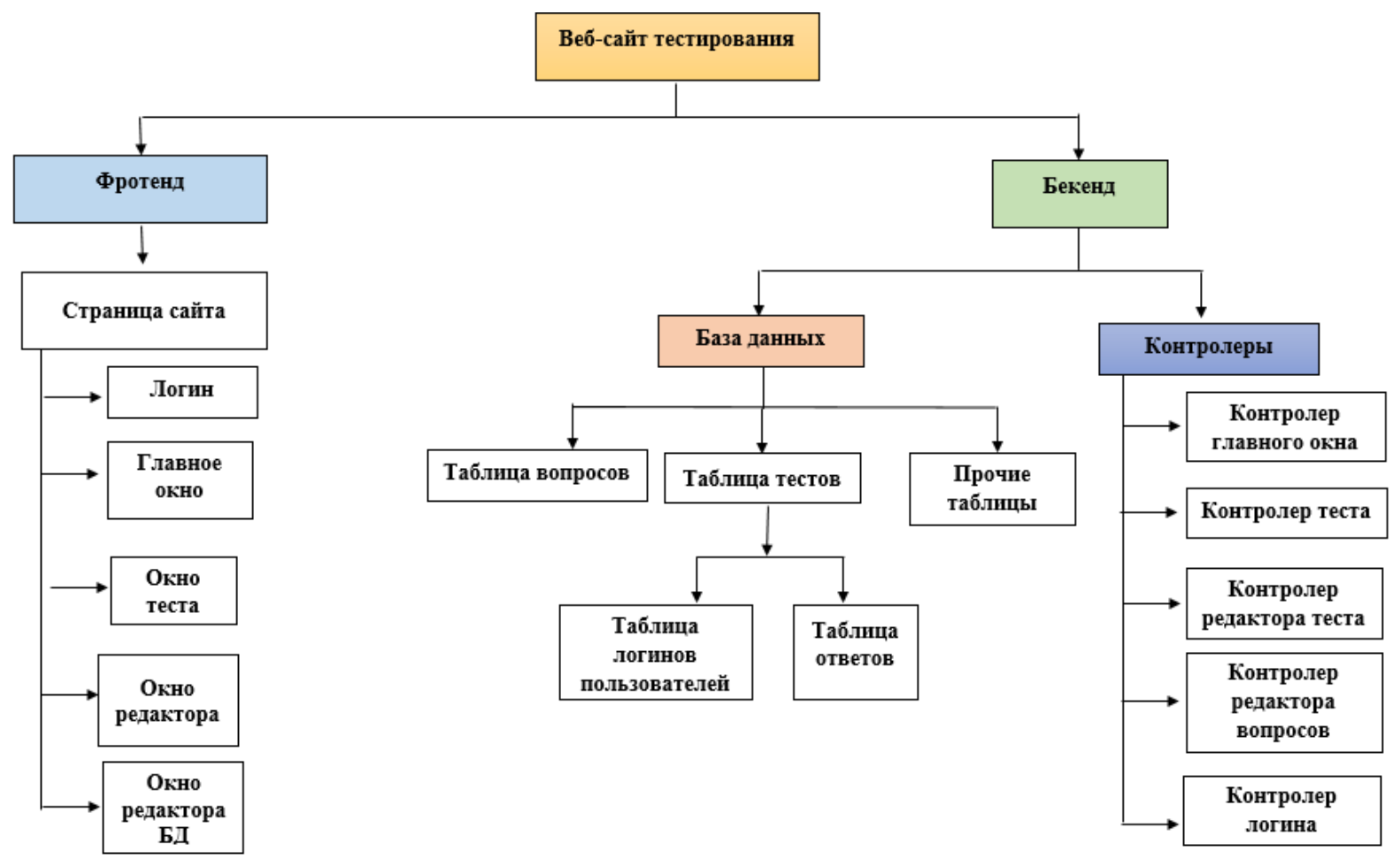

Рисунок 4. Структура веб-сайта тестирования

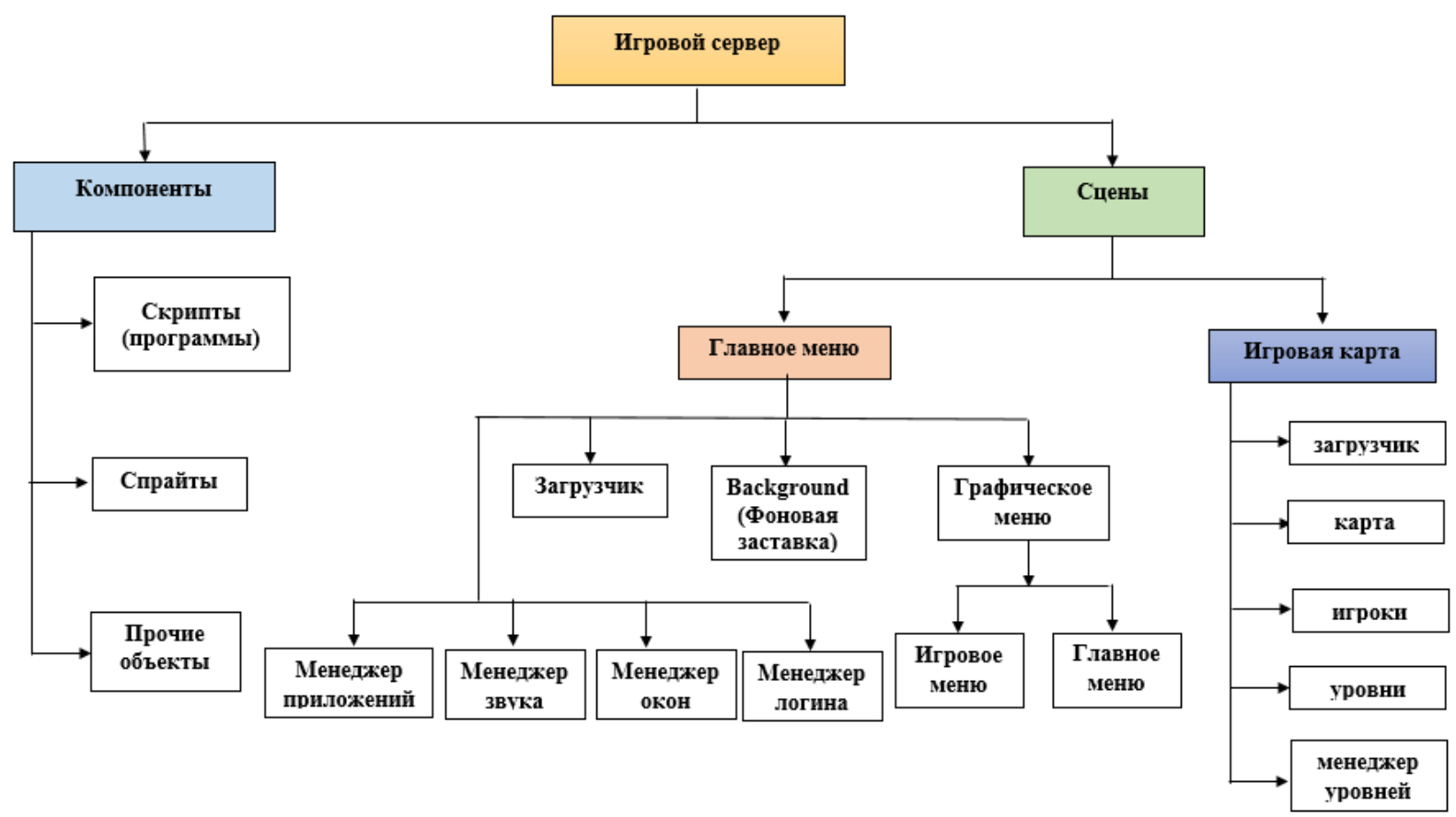

Рисунок 5. Структура игрового сервера тренажерного комплекса 


\section{Вывод}

В результате исследования разрабатываемый тренажерный комплекс для совместного обучения оперативно-диспетчерского персонала представляет собой обучающую интерактивную систему управления пожарной обстановки, содержащую все необходимые пользователю средства: первоначальной обработки данных; безинтерактивного производства принятия решений, вывода и сохранения результатов, настройки и управления режимами работы программного комплекса.

Такая система будет эффективна в деятельности предприятий и организаций в целях повышения уровня их пожарной безопасности, а также учебном процессе вузов пожарно-технического профиля при проведении научно-исследовательских экспериментов и практических занятий.

\section{Список используемых источников}

1. Устюжанина А.Ю. Концепция разработки компьютерных тренажерных комплексов для оперативно-диспетчерского состава пожарной охраны и оперативного персонала нефтегазовых предприятий // Пожарная безопасность: проблемы и перспективы: матер. VII Bcepocc. науч.-практ. конф. с междунар. участием. Воронеж, 2016. С. 210-212.

2. Шарафутдинов А.А. Совершенствование оценки эффективности совместной тренажерной подготовки персонала объектов ТЭК и личного состава пожарной охраны: автореф. ... канд. техн. наук. Уфа: Изд-во УГНТУ, 2016. 24 с.

3. Краснянский М.Н. Автоматизированная информационная система обучения персонала промышленных предприятий на основе виртуальных тренажерных комплексов // Приборы и системы. Управление, контроль, диагностика. 2013. № 11. С. 92-100. 
4. Устюжанина А.Ю. Разработка и создание веб-приложения по моделированию чрезвычайных ситуаций на опасных производственных объектах нефтегазового комплекса для совместной подготовки оперативно-диспетчерского персонала // Проблемы техносферной безопасноси-2017: матер. VI-й Междунар. науч.-практ. конф. молодых ученых и специалистов. М.: Академия ГПС МЧС России, 2017. 480 с.

5. Устюжанина А.Ю. Разработка и создание веб-приложения по моделированию чрезвычайных ситуаций на опасных производственных объектах нефтегазового комплекса // Проблемы сбора, подготовки и транспорта нефти и нефтепродуктов. 2017. № 1 (107). С. 210-218.

6. Устюжанина А.Ю. Разработка и создание веб-приложения по моделированию чрезвычайных ситуаций на опасных производственных объектах нефтегазового комплекса для совместного обучения персонала и внедрения в систему подготовки специалистов в вузе // Сб. III Междунар. молодежн. науч. конф. Липецк, 2017. 88 с.

7. Шаптала В.Г. Основы моделирования чрезвычайных ситуаций. Белгород: Изд-во БГТУ, 2010. 166 с.

8. Трухин А.В. Автоматизированная тренажерно-обучающая система: компьютерный тренажер и язык описания сценариев // Открытое и дистанционное образование. 2007. № 3 (27). С. 47-56.

9. Свойства сетей Петри. URL: https://studopedia.org/8-130451.html (дата обращения: 02.05.2018).

10. Замятина О.М. Моделирование сетей. Томск: Изд-во Томского политехнического университета, 2011. 168 с.

11. Сети Петри - математический аппарат для моделирования. URL: http://bourabai.ru/cm/petri_nets.htm (дата обращения: 01.05.2018).

12. Динамическая система. URL: http://ru.vlab.wikia.com (дата обращения: 07.05.2018). 
13. Симанков В.С. Системная динамическая модель управления процессом ликвидации кризисных ситуаций с использованием сетей Петри // Программные продукты и системы. 2010. № 1. С. 120-123.

14. Зайцев Д.А. Решение фундаментального уравнения сетей Петри в процессе композиции функциональных подсетей // Искусственный интеллект. 2005. № 1. С. 59-68.

15. Симанков В.С. Моделирование сложных объектов в режиме реального времени на основе сетей Петри // Вестник Адыгейского государственного университета. 2012. № 4 (110). С. 202-209.

16. Питерсон Дж. Теория сетей Петри и моделирование систем. М.: Мир, 1984. 264 с.

17. Мурата Т. Сети Петри. Свойства, анализ, приложения // ТИИЭиР. 1989. T. 77. № 4. C. 41-85.

18. Хан А.А. О нахождении решения уравнения состояний сетей Петри из класса уравнений Мурата // ТИИЭР. 1989. № 44. С. 36-41.

19. Компьютерные тренажерные комплексы для обучения технологического персонала. URL: http://www.atisprocess.com/ru (дата обращения: 03.04.2018).

20. Шукшунов B.E. Проектирование тренажерно-моделирующих комплексов нового поколения // Программные продукты и системы. 2012. № 4. C. 192-200.

21. OASIS Commitees: Service Oriented Architecture (SOA). URL: http://www.oasis-open.org/committees/tc_cat.php?cat=soa (дата обращения: 11.05.2018).

22. Лисицына Л.С. Руководство пользователя компьютерной сетевой системы для проведения обучения и аттестаций. СПб.: СПбГИТМО (ТУ), 2002. $44 \mathrm{c}$. 


\section{References}

1. Ustyuzhanina A.J. Kontseptsiya razrabotki komp'yuternykh trenazhernykh kompleksov dlya operativno-dispetcherskogo sostava pozharnoy okhrany i operativnogo personala neftegazovykh predpriyatiy [Concept of Development of Computer Training Complexes for Operational Dispatching Staff of Fire Protection and Operational Personnel of Oil and Gas Enterprises]. Materialy VII Vserossiiskoi nauchno-prakticheskoi konferentsii $s$ mezhdunarodnym uchastiem «Pozharnaya bezopasnost': problemy $i$ perspektivy» [Proceedings of the VII All-Russian Scientific and Practical Conference with International Participation «Fire Safety: Problems and Prospects»]. Voronezh, 2016. pp. 210-212. [in Russian].

2. Sharafutdinov A.A. Sovershenstvovanie otsenki effektivnosti sovmestnoy trenazhernoy podgotovki personala ob"ektov TEK $i$ lichnogo sostava pozharnoy okhrany: avtoref. kand. tekhn. nauk [Improving the Assessment of the Effectiveness of joint Training of Personnel of Fuel and Energy Facilities and Fire Protection Personnel: Cand. Engin. Sci. Avtoref.]. Ufa, USPTU, 2016. 24 p. [in Russian].

3. Krasnyanskiy M.N. Avtomatizirovannaya informatsionnaya sistema obucheniya personala promyshlennykh predpriyatiy na osnove virtual'nykh trenazhernykh kompleksov [Automated Information System for Training Personnel of Industrial Enterprises on the Basis of Virtual Training Complexes]. Pribory i sistemy. Upravlenie, kontrol', diagnostika - Devices and Systems. Management, Control, Diagnostics, 2013, No. 11, pp. 92-100. [in Russian]. 
4. Ustyuzhanina A.J. Razrabotka i sozdanie veb-prilozheniya po modelirovaniyu chrezvychaynykh situatsiy na opasnykh proizvodstvennykh ob"ektakh neftegazovogo kompleksa dlya sovmestnoy podgotovki operativnodispetcherskogo personala [Development and Creation of a Web Application for Modeling Emergencies at Hazardous Production Facilities of the Oil and Gas Complex for Joint Training of Operational and Dispatching Personnel]. Materialy VI mezhdunarodnoy nauchno-prakticheskoy konferentsii molodykh uchenykh i spetsialistov «Problemy tekhnosfernoy bezopasnosi-2017» [Materials of the VI International Scientific and Practical Conference of Young Scientists and Specialists «Problems of Technosphere Safety-2017»]. Moscow, Academy of State Fire Service of EMERCOM of Russia, 2017. 480 p. [in Russian].

5. Ustyuzhanina A.J. Razrabotka i sozdanie veb-prilozheniya po modelirovaniyu chrezvychaynykh situatsiy na opasnykh proizvodstvennykh ob"ektakh neftegazovogo kompleksa [Development and Creation of a Web Application for Modeling Emergencies at Hazardous Production Facilities of the Oil and Gas Complex]. Problemy sbora, podgotovki $i$ transporta nefti $i$ nefteproduktov - Problems of Gathering, Treatment and Transportation of Oil and Oil Products, 2017, No. 1 (107). pp. 210-218. [in Russian].

6. Ustyuzhanina A.J. Razrabotka i sozdanie veb-prilozheniya po modelirovanii chrezvychaynykh situatsiy na opasnykh proizvodstvennykh ob"ektakh neftegazovogo kompleksa dlya sovmestnogo obucheniya personala i vnedreniya $\mathrm{v}$ sistemu podgotovki spetsialistov $\mathrm{v}$ vuze [Development and Creation of a Web Application for Modeling Emergencies at Hazardous Production Facilities of the Oil and Gas Complex for Joint Training of Personnel and Implementation in the Training System at the University]. Sbornik III Mezhdunarodnoy molodezhnoy nauchnoy konferentsii [Collection of III International Youth Scientific Conference]. Lipetsk, 2017. 88 p. [in Russian].

7. Shaptala V.G. Osnovy modelirovaniya chrezvychainykh situatsii [Basics of Modeling of Emergencies]. Belgorod, BSTU Publ., 2010. 166 p. [in Russian]. 
8. Trukhin A.V. Avtomatizirovannaya trenazherno-obuchayushchaya sistema: komp'yuternyy trenazher i yazyk opisaniya stsenariev [Automated Training System: Computer Simulator and Script Language]. Otkrytoe $i$ distantsionnoe obrazovanie - Open and Distance Education, 2007. No. 3 (27), pp. 47-56. [in Russian].

9. Svoistva setei Petri [Properties of Petri Nets]. Available at: https://studopedia.org/8-130451.html (accessed 02.05.2018). [in Russian].

10. Zamyatina O.M. Modelirovanie setei [Network Modeling]. Tomsk, TPU Publ., 2011. 168 p. [in Russian].

11. Seti Petri - matematicheskii apparat dlya modelirovaniya [Petri Nets Mathematical Apparatus for Modeling]. Available at: http://bourabai.ru/cm/petri_nets.htm (accessed 01.05.2018). [in Russian].

12. Dinamicheskaya sistema [Dynamical System]. Available at: http://ru.vlab.wikia.com (accessed 07.05.2018). [in Russian].

13. Simankov B.C. Sistemnaya dinamicheskaya model' upravleniya protsessom likvidatsii krizisnykh situatsiy s ispol'zovaniem setey Petri [System Dynamic Model of Crisis Management Using Petri Nets]. Programmnye produkty i sistemy - Software Products and Systems, 2010, No. 1, pp. 120-123. [in Russian].

14. Zaytsev D.A. Reshenie fundamental'nogo uravneniya setey Petri v protsesse kompozitsii funktsional'nykh podsetey [Solution of the Fundamental Equation of Petri Nets in the Process of Functional Subnets Composition]. Iskusstvennyy intellect - Artificial Intelligence, 2005, No. 1, pp. 59-68. [in Russian].

15. Simankov B.C. Modelirovanie slozhnykh ob"ektov v rezhime real'nogo vremeni na osnove setey Petri [Real-Time Modeling of Complex Objects Based on Petri Nets]. Vestnik Adygeiskogo gosudarstvennogo universiteta - The Bulletin of the Adyghe State University, 2012, No. 4 (110), pp. 202-209. [in Russian]. 
16. Peterson G. Teoriya setei Petri i modelirovanie sistem [Petri Nets Theory and Systems Modeling]. Moscow, Mir Publ., 1984. 264 p. [in Russian].

17. Murata T. Seti Petri. Svoistva, analiz, prilozheniya [Properties, Analysis, Applications]. Trudy instituta inzhenerov po elektrotekhnike i radioelektronikeProceedings of the IEEE, 1989, Vol. 77, No. 4, pp. 41-85. [in Russian].

18. Khan A.A. O nakhozhdenii resheniya uravneniya sostoyanii setei Petri iz klassa uravnenii Murata [On Finding a Solution to the Equation of States of Petri Nets from the Class of Murat Equations]. Trudy instituta inzhenerov po elektrotekhnike i radioelektronike - Proceedings of the IEEE, 1989, No. 44, pp. 36-41. [in Russian].

19. Komp'yuternye trenazhernye kompleksy dlya obucheniya tekhnologicheskogo personala [Computer Simulators for Training of Technological Personnel]. Available at: http://www.atisprocess.com/ru (accessed 03.04.2018). [in Russian].

20. Shukshunov V.E. Proektirovanie trenazherno-modeliruyushchikh kompleksov novogo pokoleniya [Design of Training and Modeling Complexes of New Generation]. Programmnye produkty i sistemy - Software and Systems, 2012, No. 4, pp. 192-200. [in Russian].

21. OASIS Commitees: Service Oriented Architecture (SOA). Available at: http://www.oasis-open.org/committees/tc_cat.php?cat=soa (accessed 11.05.2018).

22. Lisitsyna L.S. Rukovodstvo pol'zovatelya komp'yuternoi setevoi sistemy dlya provedeniya obucheniya $i$ attestatsii [User's Manual of the Computer Network System for Training and Certifications]. St. Petersburg, ITMO University Publ., 2002. 44 p. [in Russian]. 


\section{Сведения об авторах}

\section{About the authors}

Котельникова Анастасия Юрьевна, ассистент кафедры «Комплексный инжиниринг и компьютерная графика», ассистент кафедры «Газохимия и моделирование химико-технологических процессов», УГНТУ, г. Уфа, Российская Федерация

Anastasia Ju. Kotelnikova, Assistant of Integrated Engineering and Computer Graphics Department, Assistant of Gas Chemistry and Modeling of Chemical Processes Department, USPTU, Ufa, Russian Federation e-mail: anastasfudo@mail.ru

Котельников Дмитрий Алексеевич, магистрант 1-го курса кафедры «Газохимия и моделирование химико-технологических процессов», УГНТУ, г. Уфа, Российская Федерация

Dmitry A. Kotelnikov, 1st Year Undergraduate Student of Gas Chemistry and Modeling of Chemical Processes Department, USPTU, Ufa, Russian Federation

e-mail:dkotel@outlook.com

Устюжанина Светлана Юрьевна, доцент кафедры «Комплексный инжиниринг и компьютерная графика», УГНТУ, г. Уфа, Российская Федерация

Svetlana Ju. Ustyuzhanina, Assistant Professor of Integrated Engineering and Computer Graphics Department, USPTU, Ufa, Russian Federation e-mail: swetaust_1@mail.ru 